\title{
Compatibility of Polymer and Remediation Agents for Enhanced Soil Remediation
}

\author{
Yunsong Liu, ${ }^{1, a}$, Jiajun Chen ${ }^{1, b}$, Xingwei Wang ${ }^{1, c}$, Meng Wei ${ }^{1, d}$, Lanxiang Shi ${ }^{1, e}$
}

${ }^{1}$ Key Laboratory for Water and Sediment Sciences of Ministry of Education, School of Environment, Beijing Normal University, Beijing 100875, China

aliuyunsong@mail.bnu.edu.cn, bjeffchen@bnu.edu.cn, 'cwangxingwei0812@gmail.com, dweimeng@mail.bnu.edu.cn, ${ }^{\mathrm{e}} 201521180068 @$ mail.bnu.edu.cn

Keywords: Xanthan; Remediation agents; Compatibility; In-situ soil remediation

Abstract: Polymer flooding, as a promising method, can deliver conventional oil-displacing agents effectively to contaminants distributed within heterogeneous soil. In this study, combinations of polymer (xanthan) and common remediation agents (potassium permanganate and/or sodium persulfate) were used for polymer-enhanced in situ chemical oxidation applications. The concentrations and solution viscosities of remediation agents were utilized as initial measures of compatibility. Chemical reactions were determined between the xanthan and remediation agents within 72 hours. The results showed that the viscosity of solution fell to the lowest at the fourth hour, and it was decreased by more than $55 \%$ after $72 \mathrm{~h}$ of reaction with sodium persulfate. Furthermore, xanthan consumption in xanthan/remediation agents combinations appeared to be correlated with xanthan concentrations. These advantages such as high viscosity retention, moderate remediation agents demand make xanthan/remediation agents become the most compatible for polymer-enhanced soil remediation.

\section{Introduction}

Polymer floods can enhance oil recovery (EOR) in the oil industry. The essence of improving displacement efficiency in polymer flooding lies in the fact that polymer flooding can increase the oil/water mobility ratio, break the "equilibrium" system to divert waterways, and redistribute oil saturation [1]. However, literature shows few applications of polymer floods in environmental field, especial for soil remediation. The increased sweep efficiency provided by polymer floods can aid the delivery of chemical oxidants to lower-permeability layers and increase the effectiveness of remediation in heterogeneous porous media [2]. There are several important characteristics that must be tested before injecting polymer solution into a formation, including low cost, good filtration properties, suitable viscosity, surfactant compatibility, salinity and calcium tolerance, thermal stability, mechanical stability, good injectivity, good transport in reservoir rocks, and low retention on rock surfaces [3]. Since the viscosity of polymer solution is dramatically affected by the polymer molecular weight, concentration and the degree of hydrolysis, which will significantly affect the performance of polymer flooding and oil recovery value [4].

The mobility of fluid reduced with the increase of viscosity in higher permeable strata, and the reduction of mobility promotes the cross-flow flow into adjacent lower permeable strata [5]. xanthan solutions coupled with the remediation agents potassium permanganate $\left(\mathrm{KMnO}_{4}\right)$ and sodium persulfate $\left(\mathrm{Na}_{2} \mathrm{~S}_{2} \mathrm{O}_{8}\right)$ were utilized in our polymer/remediation agents compatibility experiments.

Two primary screening criteria refer to measuring compatibility and suitability of polymer and remediation agents, namely the viscosity of polymer/remediation agents through time and concentration of remediation agents through time.

\section{Experimental Methods}

Materials. Xanthan powders, potassium permanganate $\left(\mathrm{KMnO}_{4}\right)(99 \%)$ and sodium persulfate $\left(\mathrm{Na}_{2} \mathrm{~S}_{2} \mathrm{O}_{8}\right)(99 \%)$ were purchased and used as received. 
Methods. Polymer were slowly added as solid powders to deionized water at 45 temperatures and stirred for 2 3 hours with a mixer. It was rested at least 12 hours before the experiment. The standard curves of xanthan, potassium permanganate and sodium persulfate were drawn prior to these experiments. The concentrations gradient of xanthan, potassium permanganate and sodium persulfate were 50,100, 200, 400, 800 and $1600 \mathrm{mg} / \mathrm{L}$, respectively.

Batch tests containing stock solutions of each xanthan formulation with each remediation agents created by use of 1:1 mixing ratios by volume. Remediation agents concentrations were monitored at $0,4,8,12,24,48,72 \mathrm{~h}$ intervals; a Hach DR-6000 spectrophotometer was used at $585 \mathrm{~nm}$ for potassium permanganate and $203 \mathrm{~nm}$ for sodium persulfate quantification. Two or three individual samples were taken from each experiment.

\section{Results and Discussions}

Column Punch Experiments. Column type: length $L=15 \mathrm{~cm}$; diameter $\Phi=5 \mathrm{~cm}$; quartz sand is 10 20 mesh; filtration membrane selected $0.22 \mu \mathrm{m}$ aperture.

Experimental conditions: $50 \mathrm{ml}$ centrifuge tube shock centrifuged for 20 minutes (3000 $\mathrm{rpm} / \mathrm{min}$ ). Column punch experimental device is shown in Fig. 1.

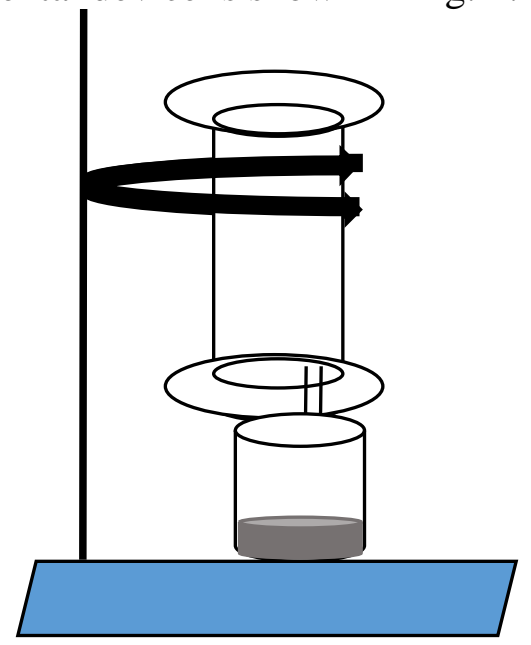

Fig. 1 Device of column punch

The column punch experimental results were shown in Table 1 . The viscosity increased with the increase of xanthan concentration. The absorption rate was more than $99 \%$ (Table 1). The first concentration (concentration1) referred to initial concentration. The second concentration (concentration2) referred to outflow concentration through column.

Table 1 Column punch experimental results

\begin{tabular}{cccccc}
\hline $\begin{array}{c}\text { concentration1 } \\
{[\mathrm{mg} / \mathrm{L}]}\end{array}$ & $\begin{array}{c}\text { original volume } \\
{[\mathrm{ml}]}\end{array}$ & $\begin{array}{c}\text { discharged volume } \\
{[\mathrm{ml}]}\end{array}$ & $\begin{array}{c}\text { time } \\
{[\mathrm{s}]}\end{array}$ & $\begin{array}{c}\text { Concentration2 } \\
{[\mathrm{ml}]}\end{array}$ & $\begin{array}{c}\text { Absorption } \\
\text { rate }\end{array}$ \\
\hline 50 & 300 & 263 & 7 & 0.199 & $99.60 \%$ \\
100 & 300 & 270 & 9 & 0.251 & $99.75 \%$ \\
200 & 200 & 166 & 10 & 0.383 & $99.81 \%$ \\
400 & 200 & 165 & 13 & 0.552 & $99.86 \%$ \\
800 & 200 & 154 & 26 & 0.764 & $99.90 \%$ \\
\hline
\end{tabular}

Viscosity and Oxidant Demand. The xanthan and remediation agents were mixed as ratio of 1:1 (v: $\mathrm{v})$, then testing the viscosity of xanthan/remediation agents solutions mixture and the concentration of potassium permanganate after $0,4,24,48,72 \mathrm{~h}$. 4\# xanthan referred to $400 \mathrm{mg} / \mathrm{L}$ xanthan; 4, 5\# potassium permanganate referred to $400,800 \mathrm{mg} / \mathrm{L}$ potassium permanganate, respectively. $0 \mathrm{~h}$ referred to original viscosity of xanthan without adding potassium permanganate, as shown in table 2. 
Table 2 The results of xanthan viscosity and potassium permanganate concentration

\begin{tabular}{cccccc}
\hline $\begin{array}{c}\text { Time } \\
{[\mathrm{h}]}\end{array}$ & $\begin{array}{c}\text { 4\# xanthan } \\
{[\mathrm{s}]}\end{array}$ & $\begin{array}{c}\text { 5\# potassium } \\
\text { permanganate }[\mathrm{mg} / \mathrm{L}]\end{array}$ & $\begin{array}{c}\text { Time } \\
{[\mathrm{h}]}\end{array}$ & $\begin{array}{c}\text { 4\# xanthan } \\
{[\mathrm{s}]}\end{array}$ & $\begin{array}{c}\text { 4\# potassium } \\
\text { permanganate[mg/L] }\end{array}$ \\
\hline 0 & 80 & 400.00 & 0 & 80 & 200.00 \\
4 & 49 & 403.94 & 4 & 51 & 202.47 \\
24 & 49 & 412.94 & 24 & 51 & 200.47 \\
48 & 50 & 420.61 & 48 & 51 & 201.35 \\
72 & 51 & 447.44 & 72 & 51 & 207.00 \\
\hline
\end{tabular}

Potassium permanganate could influence xanthan viscosity and the consumption by more than $36 \%$. The viscosity of solution fell to the lowest at the fourth hour, as shown in Fig. 2 (a) However, negligible influence of xanthan on the concentration of potassium within the tested range, as shown in Fig. 2 (b).
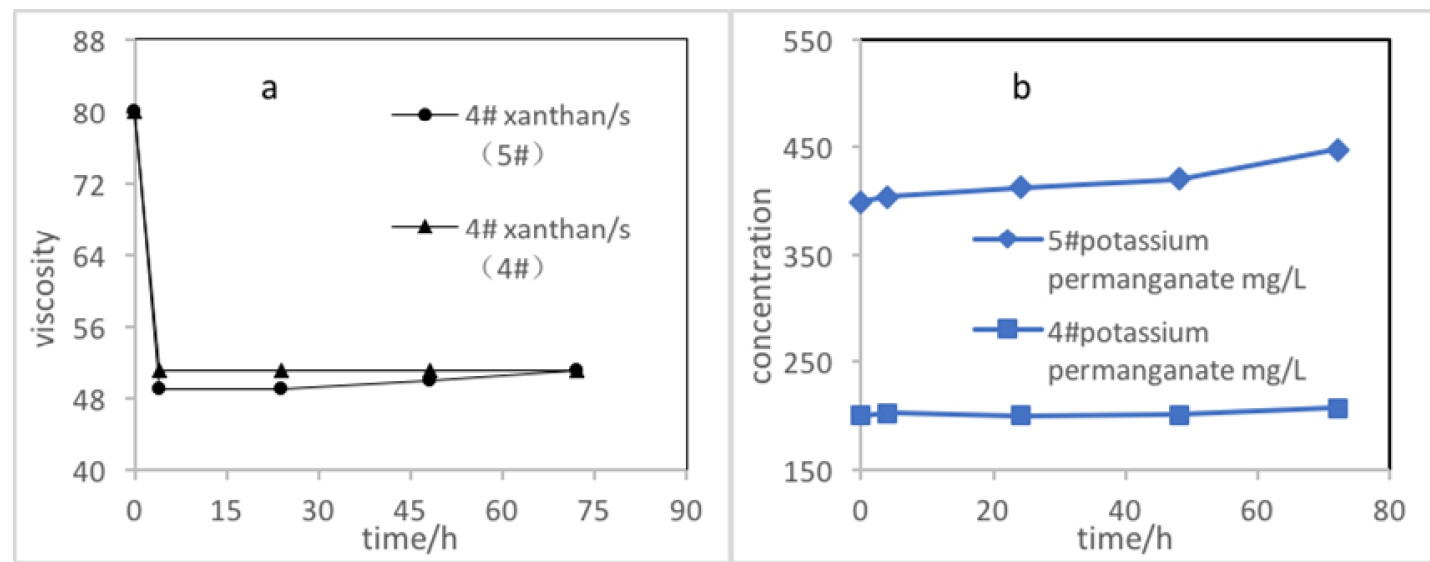

Fig. 2 Xanthan viscosity and potassium permanganate concentration versus time

Xanthan/remediation agents solutions viscosity and concentration of sodium persulfate after 0,4 , $8,12,24,48 \mathrm{~h}$ were tested. 3, 5\# xanthan referred to $200,800 \mathrm{mg} / \mathrm{L}$ xanthan, respectively; 4, 5\# sodium persulfate referred to $400,800 \mathrm{mg} / \mathrm{L}$ sodium persulfate, respectively. $0 \mathrm{~h}$ referred to original viscosity of xanthan (5\# and 3\#) without adding potassium permanganate, as shown in table 3 .

Table 3 The results of xanthan viscosity and sodium persulfate concentration

\begin{tabular}{cccccc}
\hline $\begin{array}{c}\text { Time } \\
{[\mathrm{h}]}\end{array}$ & $\begin{array}{c}\text { 5\# xanthan } \\
{[\mathrm{s}]}\end{array}$ & $\begin{array}{c}\text { 5\# sodium } \\
\text { persulfate }[\mathrm{mg} / \mathrm{L}]\end{array}$ & $\begin{array}{c}\text { Time } \\
{[\mathrm{h}]}\end{array}$ & $\begin{array}{c}\text { 3\# xanthan } \\
{[\mathrm{s}]}\end{array}$ & $\begin{array}{c}\text { 4\# sodium } \\
\text { persulfate }[\mathrm{mg} / \mathrm{L}]\end{array}$ \\
\hline 0 & 157 & 400.00 & 0 & 57 & 200.00 \\
4 & 69 & 589.54 & 4 & 43 & 251.37 \\
8 & 70 & 588.69 & 8 & 42 & 251.96 \\
12 & 71 & 593.65 & 12 & 43 & 253.87 \\
24 & 72 & 598.99 & 24 & 44 & 256.15 \\
48 & 72 & 607.78 & 48 & 43 & 260.40 \\
\hline
\end{tabular}

Sodium persulfate could influence xanthan viscosity and the consumption by more than 55\% for 5\# xanthan. The viscosity of solution fell to the lowest at the fourth hour, as shown in Fig. 3 (a). However, xanthan almost did not reduce the concentration of potassium permanganate and inhibited its diluting, the value was stable after the fourth hour as shown in Fig. 3 (b). 

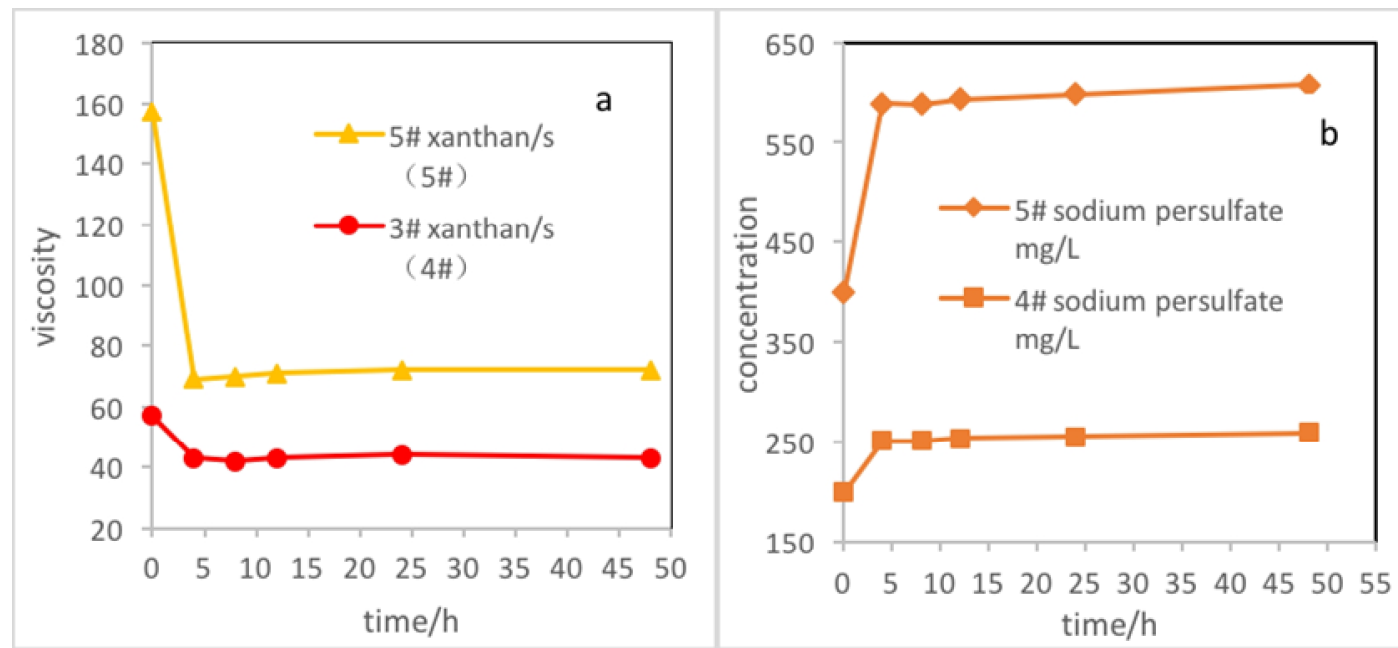

Fig. 3 xanthan viscosity and sodium persulfate concentration versus time

Discussions. Xanthan can enhance media inhomogeneity and make remediation agents uniformly distribute within heterogeneous soil. Our work found xanthan and remediation agents were compatible, moreover, the compatibility between xanthan and sodium persulfate was better than the compatibility between xanthan and potassium permanganate.

Conclusions. Follow-up study will focus on optimizing polymer and remediation agents concentration, comparing injection strategies and designing guidelines for implementation. The obtained results can be helpful in predicting the compatibility of others polymer. The further potential possibilities of xanthan-remediation agents treatment for soil remediation in situ will be studied.

\section{Acknowledgement}

This work was financially supported by the National Natural Science Foundation of China (No. 41572219) and the National Science and Technology Support Program of China (No.2012BAJ21B03-01).

\section{References}

[1] J. Hou, Z. Li, S. Zhang, X. Cao, Q. Du, and X. Song: Transport in Porous Media Vol. 79 (2009), p.417

[2] M. M. Smith, J. A. K. Silva, J. Munakata-Marr and J. E. McCray: Environ. Sci. Technol Vol. 42 (2008), p. 9296

[3] W. Yun and A. R. Kovscek: Journal of Petroleum Science and Engineering Vol. 128 (2015), p. 116

[4] H. Emami Meybodi, R. Kharrat, and X. Wang: Transport in Porous Media Vol. 89 (2011), p. 116

[5] C. Chokejaroenrat, N. Kananizadeh, C. Sakulthaew, S. Comfort, and Y. Li: Environ Sci Technol Vol. 47 (2013), p. 13031 